
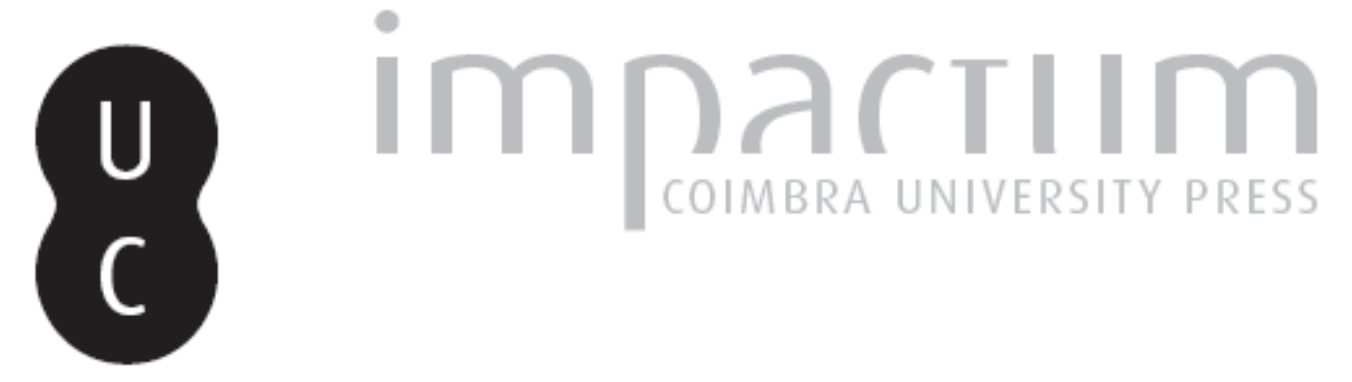

\title{
Ascensão e queda das celebridades desportivas
}

Autor(es): $\quad$ Gomes, Rui Machado

Publicado por: Imprensa da Universidade de Coimbra

URL persistente:

URI:http://hdl.handle.net/10316.2/36938

DOI:

DOI:http://dx.doi.org/10.14195/2183-6019_1_3

Accessed : $\quad$ 26-Apr-2023 10:22:47

A navegação consulta e descarregamento dos títulos inseridos nas Bibliotecas Digitais UC Digitalis, UC Pombalina e UC Impactum, pressupõem a aceitação plena e sem reservas dos Termos e Condições de Uso destas Bibliotecas Digitais, disponíveis em https://digitalis.uc.pt/pt-pt/termos.

Conforme exposto nos referidos Termos e Condições de Uso, o descarregamento de títulos de acesso restrito requer uma licença válida de autorização devendo o utilizador aceder ao(s) documento(s) a partir de um endereço de IP da instituição detentora da supramencionada licença.

Ao utilizador é apenas permitido o descarregamento para uso pessoal, pelo que o emprego do(s) título(s) descarregado(s) para outro fim, designadamente comercial, carece de autorização do respetivo autor ou editor da obra.

Na medida em que todas as obras da UC Digitalis se encontram protegidas pelo Código do Direito de Autor e Direitos Conexos e demais legislação aplicável, toda a cópia, parcial ou total, deste documento, nos casos em que é legalmente admitida, deverá conter ou fazer-se acompanhar por este aviso.

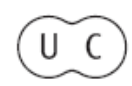


revista de comunicação,

jornalismo e espaço público

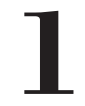

Periodicidade

Semestral

Imprensa da Universidade de Coimbra Coimbra University Press

\section{mediapolis}

os media e a construção

de personagens

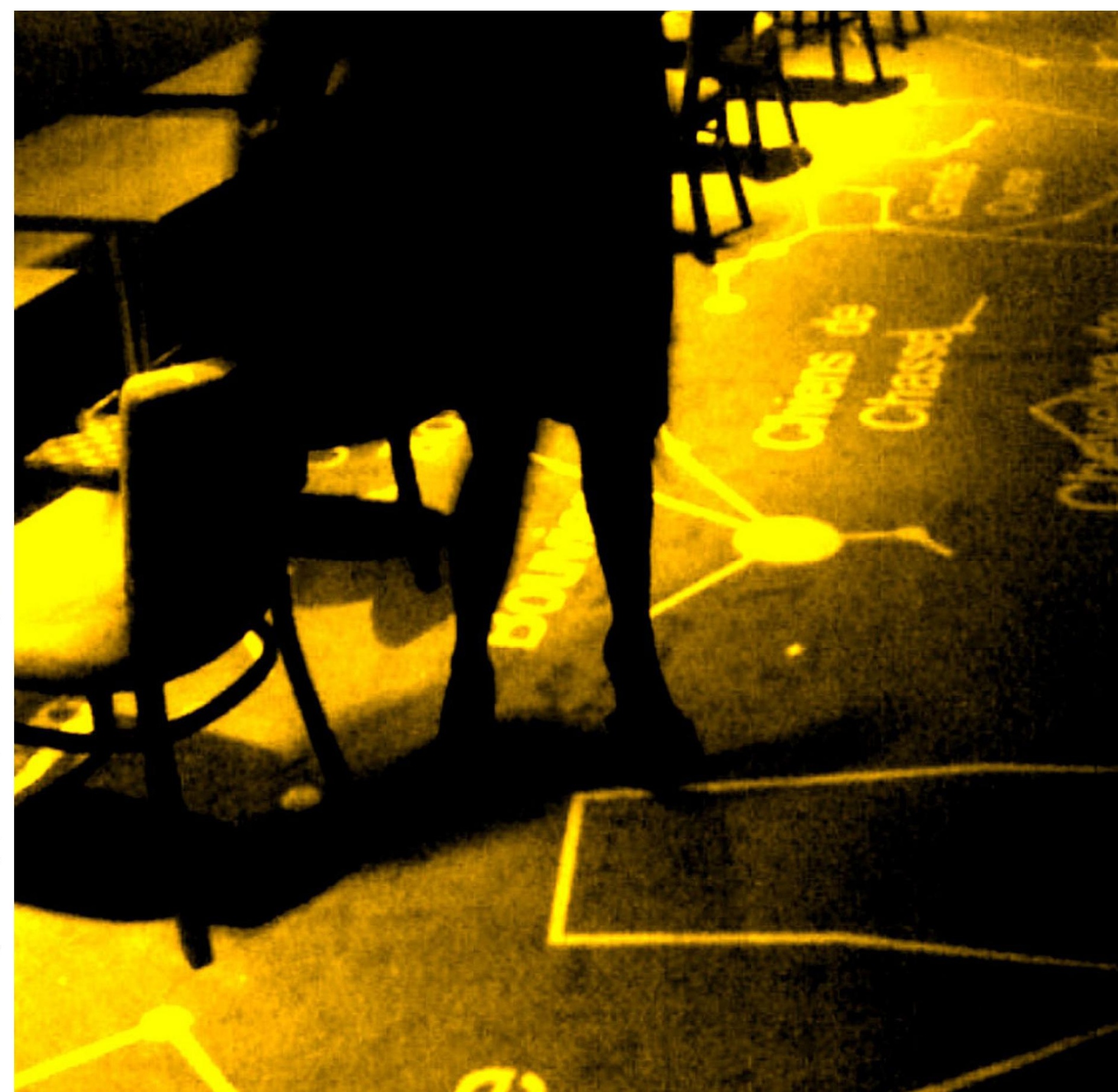




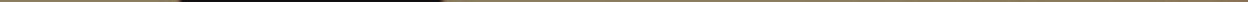




\section{Rui Machado Gomes}

Professor da Faculdade de Ciências do Desporto e de

\section{Ascensão e Queda das Celebridades Desportivas}

\section{Resumo:}

A análise crítica da construção das celebridades desportivas contemporâneas pelos meios de comunicação proporciona o enquadramento necessário à conceptualização do modo como os sujeitos usam os recursos mediáticos para a sua criatividade e para os processos de produção de identidade defendida pelo autor. Considera-se que a natureza da celebridade desportiva sofreu fortes mutações desde os anos 60, que a criação e manutenção da celebridade é em si mesma uma indústria tornada possível pelos meios de comunicação e que este processo é conduzido a partir de visões unidimensionais e maniqueístas. Os media criam com frequência narrativas que opõem os heróis e os vilões desportivos. Esta estrutura narrativa integra-se num processo mais geral da mundialização da sociedade do espectáculo. Proporcionando um alvo temporário para a consciência colectiva, os espectáculos desportivos e a iconomania que os acompanha garantem a ilusão de instantaneidade e, simultaneamente, de autoreferencialidade. Conclui-se que a universalização dos modos de vida garantidos pela desportivisão acompanha o máximo de singularização de cada um no seu espaço privado.

Palavras-chave: Celebridade; sociedade do espectáculo; iconomania; desportivisão

\section{Abstract:}

The critical analysis of the construction of the contemporary sports celebrity by the media provides the framework necessary for conceptualizing the way people use media resources for their creativity and for production of identity. It is considered that the nature of the sports celebrity suffered strong mutations since the ' 60 , that the creation and maintenance of the celebrity is in itself an industry made possible by the media and that this process is driven from one-dimensional visions. The media creates narratives that often oppose the sporting heroes and villains. This narrative structure is part of a more general process of globalization of the society of the spectacle. Providing a temporary target for the collective consciousness, the sporting performances and the iconomania guarantee the illusion of immediacy and, simultaneously, of self-referentiality. It is concluded that the universalization of the modes of life guaranteed by sport gaze accompanies the maximum of individualization of each in your private space.

Keywords: Celebrity; society of spectacle; iconomania; sport gaze. 


\section{A sociedade do espectáculo: do homem memorável ao homem calculável}

Os pós-modernistas dizem que vivemos numa sociedade do espetáculo. O lazer e a cultura popular estão verdadeiramente fascinados pelos espetáculos de massas como os grandes concertos ou os grandes eventos desportivos. A multiplicação sem fim das competições desportivas internacionais domina a perceção que hoje temos do fenómeno desportivo e, num certo sentido, do próprio mundo. Os Jogos Olímpicos, os Campeonatos do Mundo das mais diversas modalidades, os torneios de ténis e de golfe e a miríade de acontecimentos desportivos que todos os dias invadem as nossas casas constituem um dos mais poderosos veículos de fascinação das multidões. Pelo seu modo de difusão, o desporto tornou-se num dos principais motores da mundialização. Proporcionando um alvo temporário para a consciência coletiva, os espetáculos desportivos garantem a ilusão de instantaneidade e, simultaneamente, de autorreferencialidade. A universalização dos modos de vida garantidos pela desportivisão acompanha o máximo de singularização de cada um no seu espaço privado. Este não é um fenómeno recente, mas o desenvolvimento sem precedentes da homogeneização e codificação das regras desportivas em todo o planeta, bem como o controlo acrescido do fenómeno desportivo por fortes interesses financeiros, tem acentuado, nas duas últimas décadas, o seu correlato: a desportivização do mundo como metáfora por excelência da globalização. Sob o regime da difusão televisiva em direto, que permite a transmissão electrónica quase instantânea dos acontecimentos desportivos, assiste-se a uma nova espacialização planetária dominada por um tempo unificado. Ao ritmo das competições e dos calendários desportivos surgem novas ofertas nos mass media que não se limitam a transmitir acontecimentos ou a influenciar, mas são elas próprias criadoras de realidade.

A iconomania (Anders, 2001) transformou os campeões e os desportistas de alto nível em modelos publicitários e em formas de identificação juvenil; os estilos de vida, a imagem e o corpo dos novos ícones passaram a ser modelos desejáveis de sucesso
Pelo seu modo de difusão, o desporto tornou-se num dos principais motores da mundialização 
social. No início deste novo século o desporto transformou-se na indústria de entretenimento mais conhecida e mais vista em todo o globo.

No entanto, a este movimento ascendente do desporto visto não tem correspondido um movimento homólogo de atividade física e desportiva feita. Trata-se de um aspeto particular do gap mais geral entre espetacularização da sociedade e redução da experiência corporal que tem também como consequência o forte impacto das grandes vedetas desportivas no imaginário e nos desejos da cultura popular.

Embora a performance desportiva de alto nível pertença a uma lógica diferente da lógica de manutenção do corpo, a desportivização da sociedade promovida pelo olhar desportivo, ordena os comportamentos de lazer e de consumo de acordo com rituais de autodisciplina, racionalização e regularidade. O cronómetro do desportista profissional deu lugar a um cronómetro incorporado em cada um.

"O paradoxo da nossa sociedade está em, simultaneamente, pôr em cena a competição desigual do desporto-espectáculo e desenvolver o culto individual do corpo. Cada um aceita para si a busca de uma harmonia natural com o seu corpo, ao passo que colectivamente, e isso acontece cada vez mais através de intermediários interpostos, cada um se submete à ideologia combativa de corpos artificialmente profissionalizados" (Andrieu, 2004: 55).

É neste paradoxo que reside o poder mercantil das celebridades desportivas. A compreensão deste paradoxo remonta à própria génese da desportivização da sociedade. A racionalização, a quantificação e a busca constante do record são três caraterísticas que fazem do desporto um fenómeno social homólogo dos fundamentos da sociedade capitalista e da modernização. A prova desportiva e a medida da performance que a acompanha constituem as tecnologias que, no contexto desportivo, fundamentam a arte de racionalizar o gesto desportivo e, simultaneamente, estabelecem as estruturas cognitivas que tornam aceitável e necessário pessoas calculáveis (Hacking, 1986).
A medida da performance desportiva manifesta um novo poder da racionalização corporal. Em primeiro lugar, porque converte o desportista num campo racional, medível, calculável e programável; em segundo lugar, porque torna possível a constituição de um arquivo escrito sobre a performance individual do desportista e a sua posição relativa numa determinada população; em terceiro lugar, porque estabelece a norma e respectivos desvios. A consolidação desta tecnologia permitiu que a atividade desportiva, de competição, de lazer ou de saúde se desenvolva hoje sob um regime de registo, prova e graduação e a sociedade se organize segundo normas de produtividade.

Deste modo, a cultura visual inscrita na atividade desportiva inclui um regime ético para as atividades de lazer. Na verdade, aquilo que é hoje considerado uma forma "suave" de ouvir e seguir o próprio corpo (o jogging, por exemplo) é acompanhado frequentemente de sofrimentos, dietas alimentares, observação de interditos e estilos de vida típicos que conduzem o praticante ao ascetismo, vivido embora como hedonismo. 
E esse é bem o paradoxo da sociedade da desportivisão. Um novo complexo de saberpoder constituiuse com a possibilidade de estabelecer medidas objectivas do valor humano. A marca do desportista funciona, simultaneamente, como um registo de uma performance pretérita e como uma expressão quantificada do valor humano. Depois de agregadas, as marcas tornam-se numa medida da competência subjacente do sujeito, constituindo um novo modo de problematização de si face aos outros. Esta é a base racional da criação das celebridades desportivas, embora depois sejam sujeitas a um efeito de ampliação extraordinário pelos meios de comunicação.

Durante muito tempo os comportamentos individuais estiveram ao abrigo da descrição pública. Conhecer o valor de cada um, por intermédio da sua história de vida, estava reservado a um restrito grupo social que tratava de narrar os seus feitos. Em todo o caso, as narrativas de vida visavam constituir uma memóriamonumento. Com a performance desportiva não se trata de constituir uma memória futura, mas um feito para uma utilização imediata, eventual e sempre transitória. O homem memorável deu lugar ao homem calculável, sujeito à racionalidade e à mobilidade meritocrática. A celebridade desportiva é, por conseguinte, um fenómeno típico da época do homem comum. Do homem comum que pode ascender à notoriedade através da demonstração dos seus feitos. Graças ao aparelho estatístico que acompanha as técnicas de notação, registo e arquivo das marcas desportivas é possível estimar o valor de cada indivíduo e, simultaneamente, apreciar e caracterizar os grupos. Por um lado, nasce uma nova modalidade de poder, em que cada um recebe como estatuto aquilo que parece ser o seu valor intrínseco; por outro lado, instituise a repartição das diferenças individuais no conjunto da população. Num único lance, o desporto competição inicia a construção de uma estrutura de oportunidades aparentemente universal, formas de mérito padronizadas e estratégias de obtenção de estatuto e mobilidade social. A democratização da reputação dissolve o estatuto do antigo herói numa estrutura de oportunidades em que, supostamente, todos podem ter acesso ao estatuto de celebridade.
O desporto é uma construção social que, enquanto tal, representa as ideias e valores dominantes. O desporto de alta competição tem sido utilizado pelos Estados para promoverem as interpretações que procuram demonstrar como deve funcionar a vida social (Coakley, 1998). Por outro lado, o record revela as provas desportivas como uma das metáforas dominantes da conceção democrática e meritocrática da sociedade (Bromberger, 1995). Valores como o trabalho, espírito de equipa, ambição, união, esforço, modéstia, respeito e disciplina, entre outros, tornam proeminente a crença na eficácia da superação de si.

No entanto, a natureza da celebridade desportiva atual é bastante diferente da dos anos 60. Enquanto as celebridades desportivas de há 50 anos eram conhecidas pelos seus feitos desportivos, a celebridade contemporânea é apenas parcialmente construída por intermédio do seu sucesso. Com efeito, a criação e manutenção da celebridade é em si mesma uma indústria tornada possível pelos meios de comunicação. A construção de celebridades desportivas pela comunicação de massas é feita 
a partir de visões unidimensionais e maniqueístas. Os media criam com frequência narrativas que opõem os heróis e vilões desportivos. A boa conduta de Lineker é comparada com a vilania de Vinnie Jones; a brutalidade de Dennis Rodman é oposta à rectidão de Jordan. No entanto, assim como os media os podem erguer aos píncaros também os podem atirar abaixo do pedestal como os casos de Armstrong e Pistorius recentemente demonstram, ou os casos de Maradona e Gascoigne demonstraram no passado.

Grande parte da linguagem usada para descrever as estrelas desportivas vai buscar ao melodrama a sua estrutura narrativa. Os heróis sobem e caem, os vilões são derrotados e as mulheres cumprem os seus papéis de suporte aos papéis dramáticos dos homens. Neste sentido, os media cumprem um papel de educação das audiências, fazendo-as aceitar o desporto como uma espécie de melodrama. Rowe (1995) sugere que muitas celebridades desportivas ultrapassam as fronteiras entre o desporto e outras indústrias de entretenimento. As celebridades desportivas aparecem em shows televisivos, em videojogos e mesmo como estrelas convidadas em soap operas. A sua importância mediática deixou de estar restringida às carreiras desportivas. As suas vidas pessoais, transformadas em narrativas melodramáticas, são transportadas para as revistas cor-de-rosa, para os tablóides ou para os videojogos. A importância mediática não se restringe às suas carreiras desportivas, passando a sua vida pessoal a ser alvo de programas televisivos e de primeiras páginas dos jornais, como o demonstram bem os casos de Paul Gascoigne durante o Mundial de 90, ou de David Beckam há mais de uma década e mais recentemente de Cristiano Ronaldo.

Os estudos sobre os media têm uma longa tradição assente numa visão passiva das audiências, entendidas como recetáculos desta sedução produzida pelos mass media. Embora Adorno tivesse razão quando chamava a atenção para o facto de a indústria cultural se basear num sistema de dominação, essa tradição dos estudos críticos, centrada no efeito provocado pelos emissores, esquece o modo como os padrões mais globais de interacção formam e são formados pelas redes de relações sociais.
Nos anos mais recentes, alguma literatura dos estudos de comunicação e jornalismo passou a interessar-se mais pela pesquisa do modo como os sujeitos usam os recursos mediáticos para a sua criatividade e para os processos de produção de identidade. Este novo interesse, de que o modelo de Abercombrie e Longhurst (1998) do espétaculo/performance é o exemplo mais evidente, afasta-se da consideração das audiências e dos consumidores como o ponto final e culminante do processo de comunicação, considerando, em alternativa, os actos de produção das audiências e a totalidade do ciclo de produção e de consumo das notícias.

Os efeitos económicos e de reconhecimento das marcas provocado pelo envolvimento das celebridades desportivas tem sido medido com precisão. Sabe-se que os efeitos são tremendos e se medem por transacções de milhões de dólares. O que é menos claro são os motivos psicológicos, emocionais e culturais que fazem os consumidores seguir o aval que as celebridades dão às marcas. As pessoas compram ténis ou champôs devido às proezas físicas dos atletas? 
Ou porque têm confiança no seu percurso de atletas que se fizeram a si próprios? Invejam e admiram o seu sucesso material ou os consumidores são atraídos pelos seus estilos de vida construídos em torno de actividades tidas por não laborais? E poderíamos juntar muitos outros motivos.

As perguntas ilustram bem a complexidade das relações entre os desejos dos consumidores e fãs e o estatuto das celebridades. E isso só pode ser bem diagnosticado através da investigação empírica junto dos receptores das mensagens dos meios e das marcas que veiculam as celebridades desportivas. $\mathrm{O}$ que os estudos empíricos têm revelado confirma algumas hipóteses teóricas que Rojek (2001) sintetiza:

1) As celebridades desportivas transmitem-nos modelos de individualização (que alguns designam por heroísmo) numa época de estandardização e previsibilidade;

2) As celebridades desportivas são rececionadas como objetos sexuais que atraem os consumidores;

3) As celebridades expressam as vulnerabilidade humanas que, deste modo, mobilizam a simpatia e o respeito e exercem uma influência preventiva na gestão das emoções na vida quotidiana;

4) As celebridades são símbolos de sucesso material que deste modo atraem sentimentos de desejo, inveja ou desaprovação.

\section{Dos valores de uso aos valores de troca}

Uma das caraterísticas da sociedade capitalista é a transição dos valores de uso para os valores de troca como modo dominante das interacções sociais. Em sociedades dominadas pelo valor de troca, o idioma da apresentação corporal aumenta em importância social e económica. Ser atrativo e capaz de produzir desejo tornaram-se atributos procurados no mercado. $\mathrm{O}$ corpo deixa de ser um mero local de desejos e torna-se na superfície em que a distinção e a atracção são registados. $\mathrm{O}$ corpo torna-se por conseguinte numa mercadoria.

A celebridade desportiva é parte deste processo através da sua participação na cultura de distracção e entretenimento. Com o declínio do sagrado e das igrejas, os pressupostos religiosos da via da salvação viram as suas referências muito limitadas. Celebridade e espetáculo preencheram o vácuo provocado pela erosão das religiões, contribuindo para o culto da distração que valoriza o superficial e o domínio da cultura de consumo.

A passagem de uma sociedade baseada na ética do trabalho para uma sociedade de consumo provocou um conjunto de mudanças profundas. Em primeiro lugar, alterou-se o modo como se preparam e educam os sujeitos para satisfazer as condições impostas pela sua identidade social. As instituições clássicas de tipo disciplinar caíram em desuso. O tipo de treino proporcionado pelas instituições panópticas - o emprego na fábrica ou no escritório para toda a vida, o serviço militar obrigatório, a escola, etc - já não serve à formação dos novos consumidores. Enquanto a sociedade das disciplinas formatava as pessoas para comportamentos rotineiros e monótonos, eliminando ou limitando as possibilidades de escolha individual; os requisitos necessários a um bom consumidor exigem agora uma subjetividade assente num estado 


\section{A cultura de}

\section{celebridade}

não consegue

produzir valores

transcendentais.

Qualquer gesto

que vise a

transcendência

é, no limite,

cooptado pela

mercadorização. permanente de escolha, avesso a qualquer rotina.

Em segundo lugar, o modo de ação da produçãa e do consumo têm naturezas muito diversas. Enquanto a produção é uma ação coletiva que supõe a divisão de tarefas, a cooperação entre os agentes e a coordenação das suas atividades, com os consumidores passa-se justamente o contrário. O consumo coletivo não existe: trata-se de uma atividade individual, solitária, que se cumpre no livre jogo individual das sensações e desejos. Como afirma Bauman (2003), se a comunidade de produtores era essencialmente platónica, centrada que estava nas regras e na estrutura final das ações, a sociedade de consumidores é basicamente aristotélica, orientada que está por comportamentos pragmáticos e uma matriz cognitiva flexível. A liberdade de escolha é a medida que estabelece a estratificação na sociedade de consumo. Quanto maior é a liberdade de escolha sem restrições mais elevada é a posição na hierarquia social.

Uma terceira característica que marca a transição da produção para o consumo diz respeito à ética. Na feliz síntese de Bauman (2003), a nossa sociedade é uma comunidade de cartões de crédito e não de cupões de aforro. A ética protestante do trabalho, tem no uso autodisciplinado do tempo, no trabalho duro e na satisfação retardada os princípios fundamentais da automodelação dos sujeitos. O trabalho é um dever que está acompanhado por uma atitude rígida relativamente ao prazer e aos divertimentos. Pelo contrário, a estética do consumo tem na possibilidade de fazer coincidir o momento da escolha com o momento da vivência gratificante a sua principal caraterística. Por isso, as normas reguladoras do consumo são improcedentes perante uma lógica generalizada de sedução que pressagia novas emoções. Acumular primeiro para adquirir depois deixou de fazer sentido em face da estética do consumo que premeia as experiências intensas. 0 único critério válido é consumir primeiro para pagar depois, já que a noção de temporário, transitório e efémero marca todo o objecto e toda a experiência de consumo. A mercantilização do futuro que carateriza as dívidas do consumidor passa a estar intimamente associada a um trabalho de domínio de si, já que o consumo não se limita 
a uma perspectiva hedonista de just fun, constituindo uma forma básica de autoprodução da identidade.

Appadurai (2004: 95-119) desenvolveu o pressuposto do consumo enquanto vivência estética. Considerando que a competência para cada um se orientar pelos fluxos temporais abertos do crédito e da compra implica uma nova forma de trabalho, conclui que este trabalho não visa sobretudo a produção de mercadorias, mas antes a criação de condições de consciência em que pode ocorrer a compra. $\mathrm{O}$ núcleo deste trabalho é aquilo a que Appadurai chama a disciplina social da imaginação. Esta disciplina está ancorada na incorporação do prazer do efémero, ilustrada pela

curta vida de prateleira dos produtos e dos estilos de vida; a velocidade com que muda a moda; a velocidade dos gastos; os polirritmos do crédito, da aquisição e da oferta; a transitoriedade das imagens dos produtos na televisão, a aura de periodização que paira sobre os produtos e os estilos de vida na iconografia dos meios de comunicação de massas.
O desejo passa a organizar-se em torno da estética do efémero. Neste regime de consumo é no olhar e no próprio corpo que se inscrevem as principais técnicas de autodisciplina e automodelação.

\section{Coda: a cultura \\ de consumo}

Mas o que carateriza esta cultura de consumo? Em primeiro lugar é incapaz de produzir uma cultura integrada visto que apresenta cada produto como uma distinção momentânea e, portanto, efémera. Deste modo, a cultura da celebridade não consegue produzir valores transcendentais visto que qualquer gesto que vise a transcendência é, no limite, cooptado pela mercadorização. O capitalismo requer que os consumidores desenvolvam um desejo abstrato por objetos de consumo. Esta qualidade abstrata torna o desejo dos consumidores alienado na medida em que estes são conduzidos a substituir permanentemente a procura de certos objetos por outros novos, num autêntico fetichismo da mercadoria.
A cultura da celebridade é parcialmente a expressão de uma cultura organizada em torno deste desejo abstrato. Trata-se de um instrumento de mercadorização da sociedade visto que o desejo é incorporado, fornecendo aos consumidores padrões de emulação obrigatórios. A cultura de celebridade é um dos mais importantes mecanismos de mobilização do desejo. Desde logo porque materializa o desejo num objecto animado que permite níveis mais profundos de ligação e identificação. A celebridade pode ser reinventada para renovar o desejo e o envelhecimento dos ícones desportivos pode mesmo funcionar como um ponto a favor do seu valor de mercado desde que reciclado como objeto de nostalgia. Os exemplos de Boby Charlton, McEnroe e outros demonstram que o envelhecimento e mesmo a morte não são um impedimento ao processo de mercadorização.

O mundo das celebridades é um mundo que repousa na opinião. A renúncia ao segredo é o preço a pagar para aceder ao estatuto de celebridade neste mundo da notoriedade. Para ser conhecido é preciso aceitar revelar tudo sem nada esconder ao seu 
público. Existe uma verdadeira alergia ao segredo por parte dos públicos. Daí que as celebridades desportivas estejam permanentemente confrontadas com os exercícios confessionais, habitualmente realizados através dos media. As vedetas aceitam assim renunciar à sua vida privada.

No mundo baseado na opinião a relação de grandeza é uma relação de identificação. O sujeito célebre produz o público e constitui-o enquanto tal, do mesmo modo que é feito por ele. Estabelece-se assim uma relação de adesão entre o público e a celebridade que se expressa em termos de influência. As marcas permitem cristalizar numa imagem este movimento de opinião. A instrumentação dos media assegura a objetivação através dos rumores, dos ruídos e do julgamento de opinião. Ser grande neste mundo significa ter uma certa quota de presença nos meios de comunicação, um certo número de seguidores nas redes sociais, um certo volume de reações positivas da opinião pública. Ser pequeno é cair na banalidade ou ter uma imagem fluida ou indiferente. Desaparecer dos media significa ser esquecido. E é por isso que o mundo das celebridades desportivas é hoje tão sujeito a processos de erosão, esquecimento e queda abrupta. Os cinco minutos de fama de Wharol continuam a ser a alegoria do valor efémero de toda a celebridade.

\section{Bibliografia}

Abercombrie, N., Longhurst, B. (1998). Audiences: A Sociological Theory of Performance and Imagination. London: Sage.

Anders, G. (2001). L'Obsolescence de L’Homme. Paris: L'Encyclopédie des Nuisances.

Andrieu, B. (2004). A Nova Filosofia do Corpo. Lisboa: Instituto Piaget.

Appadurai, A. (2004). Dimensões culturais da globalização. Lisboa: Teorema.

Bauman, Z. (2003). Trabajo, consumismo y nuevos pobres. Barcelona: Gedisa Editorial.

Bromberger, C., Hayot, A., Mariottini, J.M. (1995). Le Match de Football: Ethnologie d'une passion partisane à Marseille, Naples et Turin. Paris: Maison des Sciences de l'Homme. Coakley, J.J. (1998). Sport in Society (6 ${ }^{\mathrm{a}}$ ed.). Boston: McGraw -Hill.
Hacking, I. (1986). Making up people. In T. C. Heller, M. Sosna e D. E. Wellberg (eds.). Reconstructing Individualism. Stanford: Stanford University Press, pp. 222-236.

Rojek, C. (2001). Celebrity. London: Reaktion Books.

Rowe, D. (1995). Popular Cultures: Rock Music, Sport and the Politics of Pleasure. London: Sage. 